\title{
Evolution and Trends Regarding the Concepts of Innovation and Invention
}

\author{
Mihai Liviu DESPA \\ Bucharest University of Economic Studies, Bucharest, Romania \\ mihai.despa@yahoo.com
}

The paper is focused on analyzing the difference between the concepts of innovation and invention in terms of trends and evolution. The research is centered on innovation with invention being a benchmark for validating results. An economic perspective regarding the differences between invention and innovation is presented. The differences between the two concepts are also analyzed from a legal point of view. The number of references to the concept of innovation, made into a large corpus of books, is analyzed from an evolutionary perspective. The concept of invention is also analyzed in terms of number of occurrences in books. A pattern is drafted for both innovation and invention. The paper tackles the interest shown by the online community in innovation compared to the interested showed in invention. Relevant data sets depict the world's most interested online communities in innovation and invention. Online communities are analyzed by country and by city. Online communities' interest in innovation and invention is measured using statistics regarding Google searches. Events that triggered picks in interest shown towards one concept or the other are identified and portrayed. Data from relevant reports that are publicly available is presented.

Keywords: Innovation, Invention, Search Trends, Public Data

1 Innovation and Invention

Innovation and invention are two different notions that should not be seen as equivalent. Invention is the first occurrence of a new idea or a new concept in regards to a product or a process [1]. Invention is not a random process but is the result of research, study or repeated attempts. Invention must be distinguished from discovery. The latter involves finding or highlighting conditions or facts still unknown. An invention has to be unique worldwide where as an innovation has to be unique locally, in a certain region or area.

Innovation is the implementation of an idea or an invention which leads to improving and perfecting a product, a method, a theory or a service with the sole purpose of accomplishing, at a higher standard, the objectives that were originally designed for [2]. From an economic point of view an innovation is regarded as an invention that has been successfully implemented and generated added value, profit, higher income or superior quality. Innovation must have a positive impact on society, economy and the political sphere. Not all inventions have the merit to be considered innovations. In the IT industry new software applications or new versions of a product are launched on the market every day. Some are adopted by users and gain notoriety but most disappear into anonymity.

Table 1. Parallel between innovation and invention

\begin{tabular}{|l|c|c|}
\hline \multicolumn{1}{|c|}{ CRITERIA } & INNOVATION & INVENTION \\
\hline New product & YES & YES \\
\hline New process & NO & YES \\
\hline New method & NO & NOS \\
\hline Commercial use & YES & YES \\
\hline Random process & YES & YES \\
\hline Intellectual property & NO & NO \\
\hline Mandatory to have a positive impact & YES & YES \\
\hline Objective evaluation criteria & NO & \\
\hline
\end{tabular}


From a legal point of view the distinction between innovation and invention comes from the fact that innovation is an improvement, a refinement of a product or technology, but only locally while the invention has to be new worldwide [3].

According to criteria depicted in Table 1 the only common element between innovation and invention their random nature. Thus both innovation and invention occur in certain scenarios as a result of random processes. Innovation and invention evolved separately and have known distinct purposes and notoriety in society. Innovation was initially regarded as a useless and damaging novelty. In the $18^{\text {th }}$ century innovation was identified with the introduction of anything deviant in political affairs and in religion. Innovation was considered heresy [10].

\section{Evolution of Occurrence in Books}

Books are a relevant indicator for determining the evolution of society's interest related to certain subjects and topics. When certain concepts are of interest they generate literature to fuel that interest. Google has setup a project to scan books and makes the content available online. For books that are no longer subject to copyright legislation the entire content is available. For books that are protected by copyright only sample content is publicly available. Using the Google Ngram Viewer [5] tool users can search the content of both copyright protected and unprotected books. Search results display the frequency of using a certain term or group of terms in books published over a specified period of time. The frequency with which a term is used into a corpus of books, published during determined period of time, depicts the interest generated by that term during that particular period of time. Books included in Google's database are published starting from 1800 and go up to 2008. Statistics are displayed for books published up to 2000 as books published between 2000 and 2008 are still being scanned and a relevant corpus is not yet met.

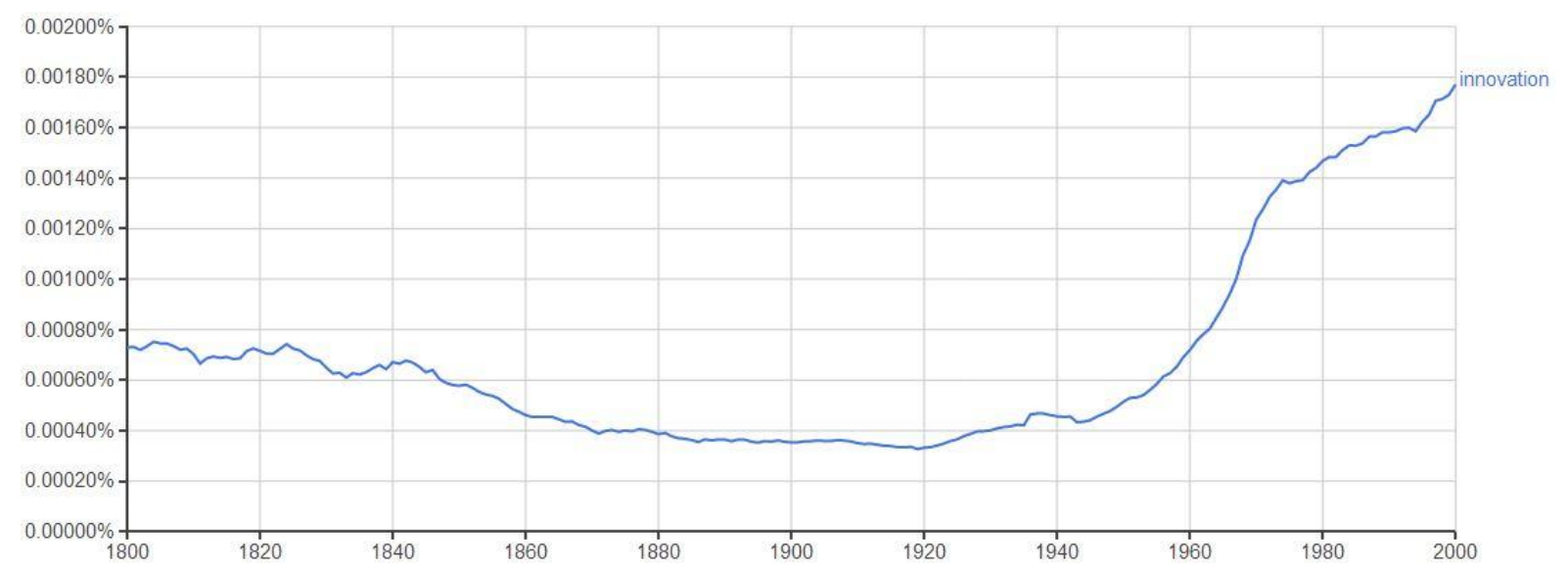

Fig. 1. Occurrence of the term innovation in the Google corpus of books [5]

Figure 1 displays the frequency of occurrence for the term innovation in the Google corpus of books starting from the year 1800 and going up to the year 2000 . Innovation was of interest in the early $19^{\text {th }}$ century. Table 2 depicts books and journals published between 1800 and 1850 that refer to innovation.
In the early $19^{\text {th }}$ century the term innovation had a pejorative connotation and it was used to describe a useless novelty. In 1835 The Westminster Review stated that Innovation is not improvement. Improvement is something new which I like; innovation is something new which I don't like. 
Table 2. Books and journals published between 1800 and 1850

\begin{tabular}{|l|l|c|}
\hline \multicolumn{1}{|c|}{ TITLE } & AUTHOR & YEAR \\
\hline $\begin{array}{l}\text { Zeal without innovation: or, The present state of religion and } \\
\text { morals considered }\end{array}$ & $\begin{array}{l}\text { James } \\
\text { Bean }\end{array}$ & 1808 \\
\hline The British Churchman & - & 1844 \\
\hline $\begin{array}{l}\text { Reform without innovation: or Cursory thoughts on the only } \\
\text { practicable reform of the Parliament }\end{array}$ & $\begin{array}{l}\text { John } \\
\text { Symmons }\end{array}$ & 1810 \\
\hline The Westminster Review & \multicolumn{1}{|c|}{-} & 1835 \\
\hline
\end{tabular}

The second part of the $19^{\text {th }}$ century saw a shift in the paradigm surrounding innovation. The term gradually became associated with improvement and progress. Table 3 depicts books and journals published between 1851 and 1900 that refer to innovation.

Table 3. Books and journals published between 1851 and 1899

\begin{tabular}{|l|c|c|}
\hline \multicolumn{1}{|c|}{ TITLE } & AUTHOR & YEAR \\
\hline $\begin{array}{l}\text { The Alarmist: Or, Fear of Innovation in the Church. By } \\
\text { a Member of the Church of England }\end{array}$ & - & 1858 \\
\hline History and Genealogy of Fenwick's Colony & Thomas Shourds & 1876 \\
\hline The Farmer's Magazine & - & 1858 \\
\hline Studies of Shakespeare & Charles Knight & 1868 \\
\hline $\begin{array}{l}\text { The Speeches of the Right Honorable John Philpot } \\
\text { Curran }\end{array}$ & $\begin{array}{l}\text { John Philpot } \\
\text { Curran }\end{array}$ & 1862 \\
\hline
\end{tabular}

On the one hand The Farmer's Magazine in 1858 still viewed innovation as an unnecessary novelty stating Prejudice opposed the improvement of fine-woolled sheep as an innovation. On the other hand The Speeches of the Right Honorable John Philpot Curran promoted innovation as an element of progress: mankind will become tired of resisting the spirit of innovation.

The early $20^{\text {th }}$ century strengthened the positive connotation of the term innovation. Table 4 depicts books and journals published between 1901 and 1950 that refer to innovation.

Table 4. Books and journals published between 1901 and 1950

\begin{tabular}{|l|l|c|}
\hline \multicolumn{1}{|c|}{ TITLE } & \multicolumn{1}{|c|}{ AUTHOR } & YEAR \\
\hline Yearbook of the National Society for the Study of Education & - & 1945 \\
\hline $\begin{array}{l}\text { The New Animal Cellular Therapy: An Innovation in } \\
\text { Therapeutics, Its Origin, Nature, Action, Uses, and New } \\
\text { Contributions to Medicine }\end{array}$ & $\begin{array}{l}\text { Joseph Roy } \\
\text { Hawley }\end{array}$ & 1901 \\
\hline The Process of Technological Innovation & $\begin{array}{l}\text { William Rupert } \\
\text { Maclaurin }\end{array}$ & 1950 \\
\hline The Academy and Literature & \multicolumn{1}{|c|}{-} & 1903 \\
\hline The Brothers Karamazov & $\begin{array}{l}\text { Fyodor } \\
\text { Dostoyevsky }\end{array}$ & 1940 \\
\hline
\end{tabular}

Novelty and scientific discovery are associated with innovation. In 1903 The Academy and Literature journal states that THE TIMES has made an innovation in the publishing trade, with a clear reference to the fact that an improvement has been introduced. In the second part of the $20^{\text {th }}$ century innovation becomes the main topic of books and interest in the term spikes as highlighted in Figure 1. Innovation moves from being a term used to portray progress and improvement to the status of becoming a concept and a trend. 
Table 5. Books and journals published between 1951 and 2000

\begin{tabular}{|l|l|c|}
\hline \multicolumn{1}{|c|}{ TITLE } & \multicolumn{1}{c|}{ AUTHOR } & YEAR \\
\hline Innovation, problems and possibilities & William Prescott & 1976 \\
\hline $\begin{array}{l}\text { Technological innovation: its environment and } \\
\text { management }\end{array}$ & - & 1967 \\
\hline Mastering the Dynamics of Innovation & $\begin{array}{l}\text { James M. } \\
\text { Utterback }\end{array}$ & 1996 \\
\hline Creativity and innovation & Ronald Mavor & 1969 \\
\hline Innovation & Kogan Page & 2000 \\
\hline
\end{tabular}

In the 1969 Creativity and innovation book innovation was referred to as a new trend that was gaining momentum: Innovation is a popular word today especially in scientific and engineering circles. The scientific community started studying innovation as a way of systematically generating progress and a method of enhancing performances.

As opposed to innovation the term invention was regarded in the early $19^{\text {th }}$ century as a positive attribute of an endeavour or product.
Inventions were protected by law and patents were issues on the name of the inventor. In the 1811 document Reports of Cases Argued and Determined in the Court of Common Pleas and Other Courts references are made to a case where legal action was being pushed for obtaining his Majesty's letters patent for the sole use and benefit of the said invention for a certain term to be specified in the said letters patent.

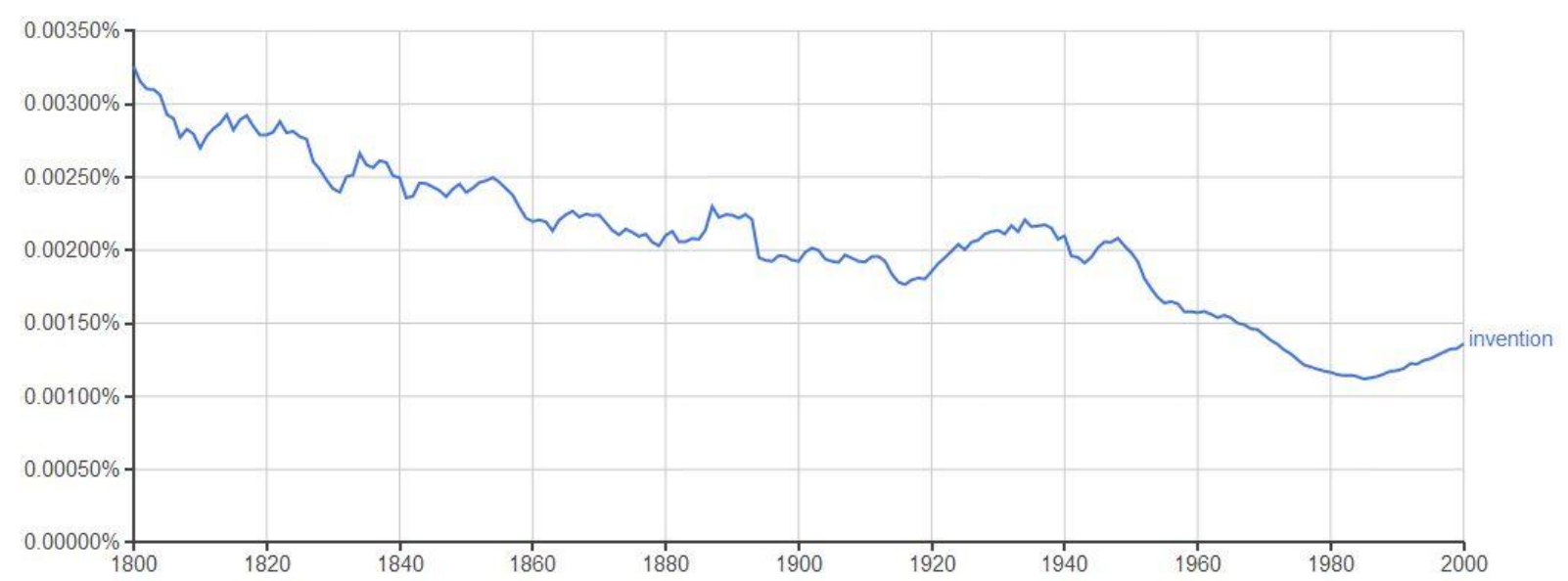

Fig. 2. Occurrence of the term invention in the Google corpus of books [5]

As presented in the Figure 2 the term invention has gradually decreased in terms of numbers of occurrences in the corpus of Google books published in the last 200 years. The situation is somewhat puzzling as the last 200 years saw a major increase in the number of inventions introduced in all area of human activity. A plausible hypothesis for this scenario is the fact interest shifted from the novelty factor to the economically viable sphere. So, innovation become more and more important as it was generating revenue and economic growth as opposed to invention which focused on generating unique results. Figure 3 presents a comparison between the interest generated by the terms innovation and invention determined as number of occurrences in the Google corpus of scanned books. 


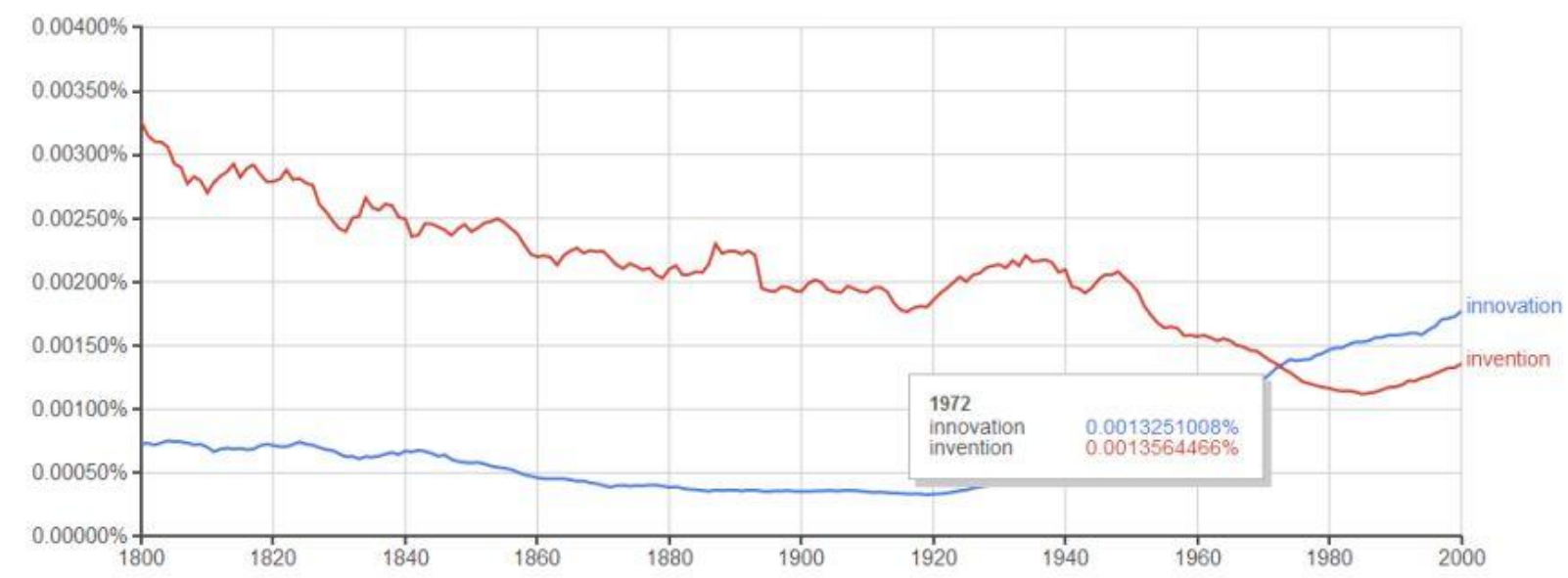

Fig. 3. Comparison between the occurrence of the terms innovation and invention [5]

In the 1800's invention was a term with a rate of occurrence of approximately 0,0032\% whereas innovation had a rate of occurrence of approximately $0,0008 \%$. In the 1800 's innovation was still perceived as a damaging process but as perceptions changed and innovation gained a more positive meaning its popularity increased. In 1972 innovation and invention were on level grounds both registering a rate of occurrence of $0,0013 \%$.

\section{Trends in Google Searches}

The beginning of the $21^{\text {st }}$ century saw a change in the way people acquire and share knowledge. Books are fast becoming deprecated in terms of mirroring people's areas of interest. The online environment is the place where people go now to acquire knowledge and share information. Websites, blogs, and forums offer information, are widely available and far less inexpensive than books. On top of all that search engines allow for fast accessing of relevant information. So in order to determine trends concerning innovation and invention suitable for the $21^{\text {st }}$ century the online environments has to be analyzed. Figure 4 presents a tool that displays in real time what are the most popular topics searched on Google worldwide on any given moment. Terms are updated constantly to reflect the searches performed all over the world.

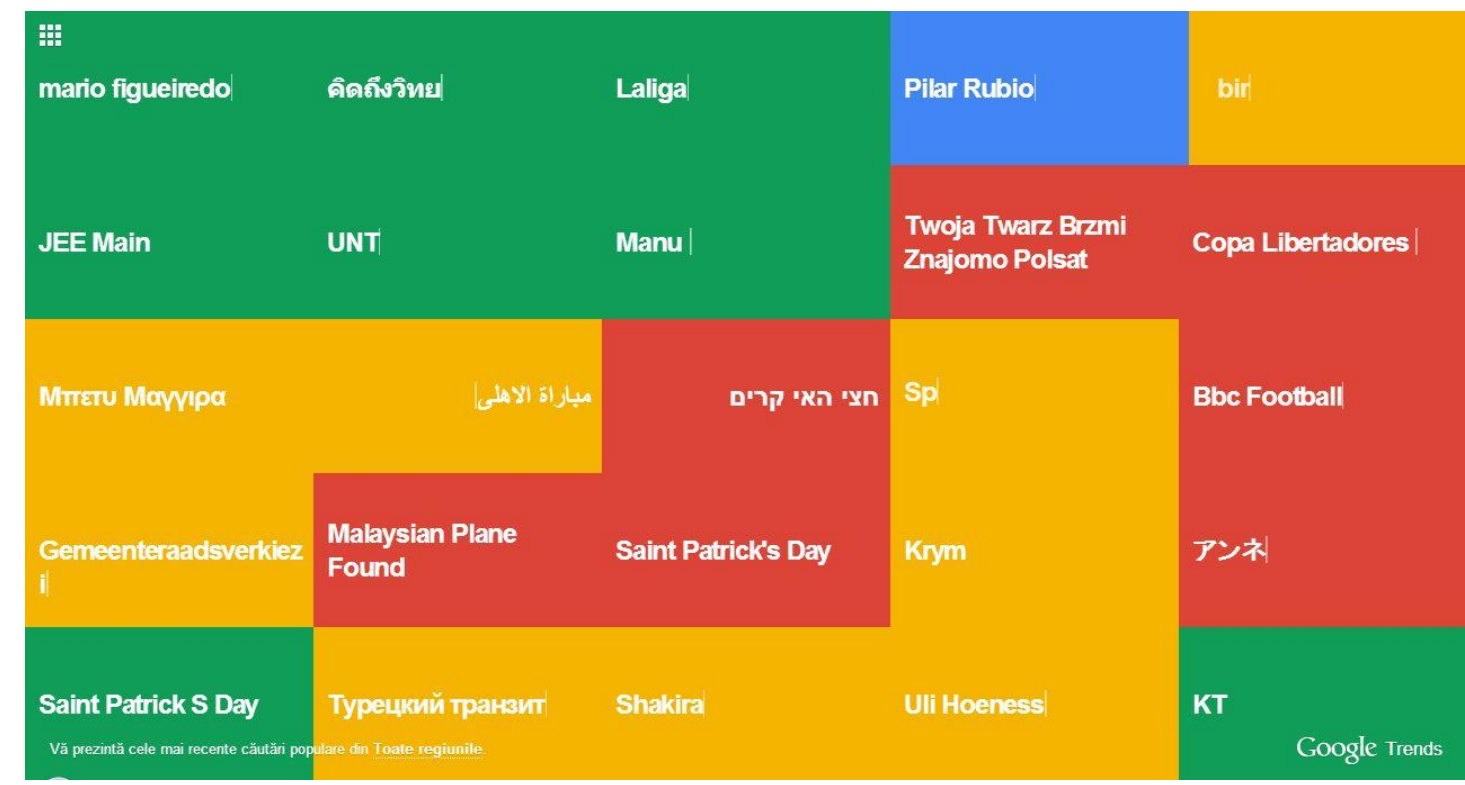

Fig. 4. Most popular Google searches worldwide in real time [6] 
Data presented in Figure 4 was obtained on 16.03.2014. It highlights an interest for the upcoming Saint Patrick's Day, the missing Malaysian plane, football events and a tax evasion scandal in Germany. All the events that keep the headlines of international media are mirrored in the top searches on Google so analyzing innovation and invention using search results is an endeavor that will show relevant results.

Figure 5 represents search data collected for Romania on 22.03.2014. Data highlights interest for political unrest in Eastern Europe, a popular cocking TV show, a popular online game, ex Formula 1 drivers and a fashion designer.

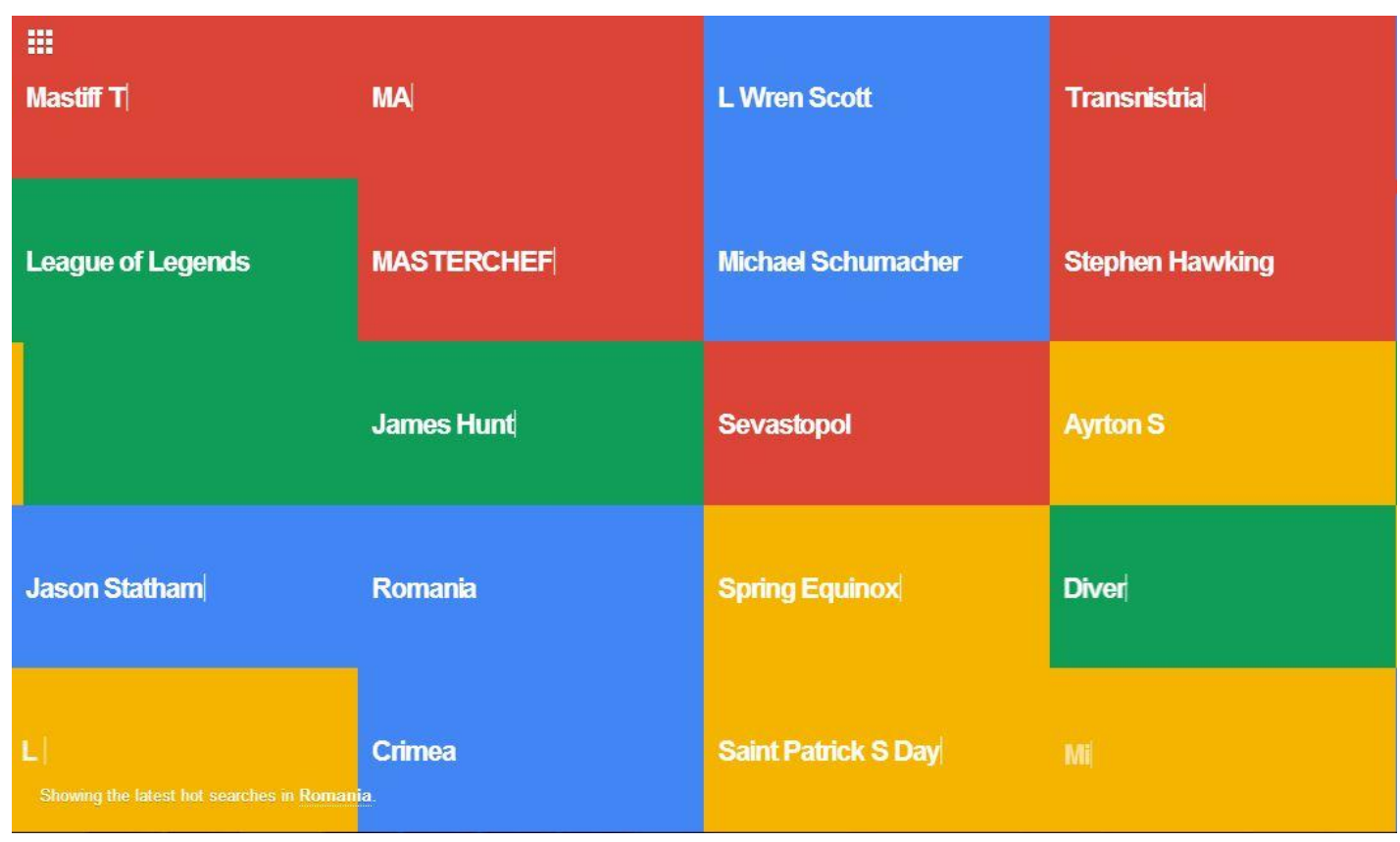

Fig. 5. Most popular Google searches in Romania [6]

Using the Google Trends tool search patterns can be determined for certain terms or group of terms. Google provides information about search statistics starting from 2004. Searches performed worldwide determine the interest of people regarding a certain subject. Figure
5 shows a comparison between the search frequency of the terms innovation and invention worldwide. The timespan that is being analyzed starts in January 2004 and ends in March 2014.

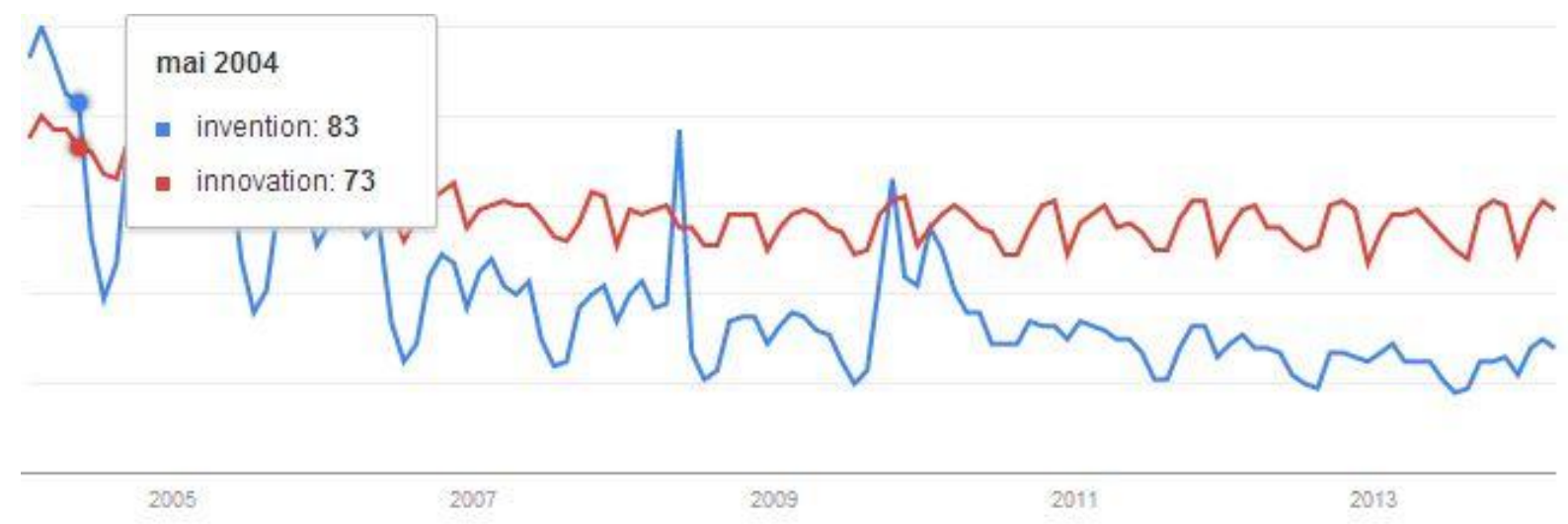

Fig. 6. Parallel between the search frequency of the terms innovation and invention [7]

The term invention starts the year 2004 as more popular than innovation but rapidly loses momentum and innovation becomes the predominant theme. Tow spikes show up in 
Figure 6 where invention overtook innovation in terms of search popularity, one in May 2008 and another in October 2009. In May 2008 events that increased interest for invention where the European Inventor Award and the Invention blog, The October 2009 spike was backed up by the Thomson Reuters scientific conference Invention Machine Hosts Worldwide User Conference in Boston and the British Invention Show which both took place in that specific timespan. Also a film that featured the word innovation in its title was launched in October 2009, namely The Invention of Lying. Using Google trends regions and countries that have the highest interest in certain fields can be determined. In order to rank countries or regions according to interest shown for a certain topic Google uses an indicator that ranges from 0 to 100 . The value of the indicator reflects how many searches have been done for a particular term, relative to the total number of searches done on Google over time originating from that particular region or country. The country with the highest ranking value gets a score of 100 and the score for the following countries is determined relative to the highest ranking value.

Table 6. Search frequency top by country for the term innovation [7]

\begin{tabular}{|l|c|}
\hline \multicolumn{1}{|c|}{ COUNTRY } & SCORE \\
\hline Botswana & 100 \\
\hline Kenya & 87 \\
\hline Rwanda & 78 \\
\hline Denmark & 69 \\
\hline Singapore & 69 \\
\hline Uganda & 69 \\
\hline Zimbabwe & 61 \\
\hline Tanzania & 59 \\
\hline Ghana & 59 \\
\hline South Africa & 57 \\
\hline
\end{tabular}

Table 6 presents the top 10 countries ranked according to search frequency for the term innovation. Results show an overwhelming

presence of countries from Africa in the top. The only European country in the top is Denmark.

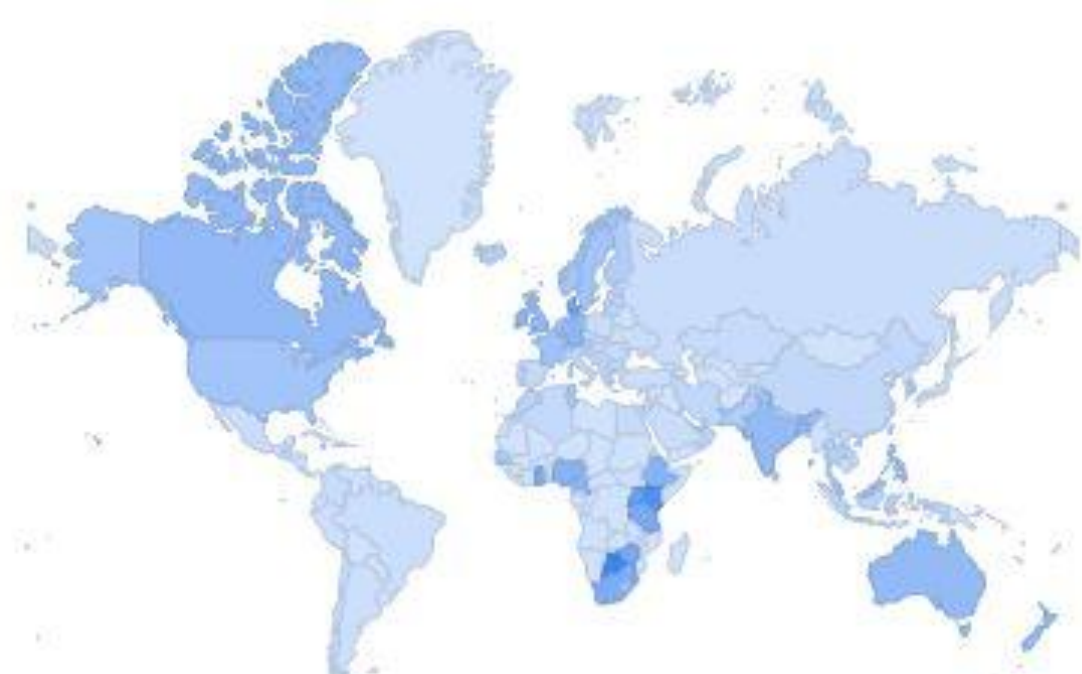

Fig. 7. Regions with high search frequency for the term innovation [7] 
Figure 7 depicts a map representation of the regions with high search frequency for the term innovation. The search frequency is proportional to the intensity of the color blue represented on the map. Countries highlighted in dark blue are characterized by a high frequency of searches for the term innovation. Besides the countries listed in Table 6, Europe with France, Germany and United Kingdome is also a region where innovation interest ranks high. In Australia and North America innovation is also a popular subject according to Google search data.

At city level Google data shows that searches targeted on innovation are popular in Europe's largest cities namely Copenhagen, Berlin, Düsseldorf, Köln and London. India's Chennai and Bengaluru are also in the top as are Toronto and Washington from North America and Singapore. From the countries that ranked in top 10 according to search frequency for the term innovation only Singapore and Denmark are also represented in the city top.

Table 7. Search frequency top by city for the term innovation [7]

\begin{tabular}{|l|c|}
\hline \multicolumn{1}{|c|}{ CITY } & SCORE \\
\hline Copenhagen & 100 \\
\hline Singapore & 92 \\
\hline Berlin & 86 \\
\hline Düsseldorf & 80 \\
\hline Köln & 75 \\
\hline Bengaluru & 73 \\
\hline Washington & 66 \\
\hline London & 58 \\
\hline Chennai & 56 \\
\hline Toronto & 54 \\
\hline
\end{tabular}

No city from Africa ranks in the top 10 innovation only in urban centres whereas presented in Table 7. This scenario highlights developing countries tackle innovation the fact that developed countries focus on nationwide.

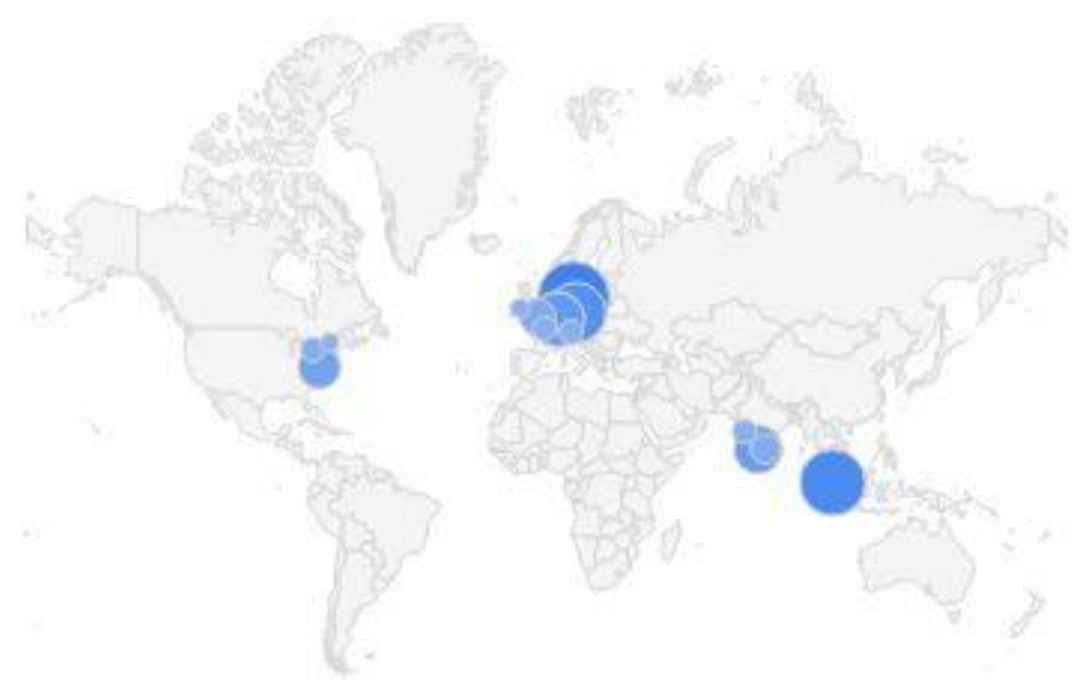

Fig. 8. - Cities with high search frequency for the term innovation [7]

Figure 7 depicts a map representation of the cities with high search frequency for the term innovation. Cities are represented by circles, the larger the circle the higher the search frequency. Also the search frequency is proportional to the intensity of the color blue 
represented on the map. Cities highlighted in dark blue are characterized by a high frequency of searches for the term innovation.

Table 8 presents the top 10 countries ranked according to search frequency for the term invention. Ranking does not take into account absolute number of searches but instead focuses on the percentage of searches that targeted invention out of the total searches performed in a country.

Table 8. Search frequency top by country for the term invention [7]

\begin{tabular}{|l|c|}
\hline \multicolumn{1}{|c|}{ COUNTRY } & SCORE \\
\hline Philippines & 100 \\
\hline USA & 53 \\
\hline France & 51 \\
\hline Canada & 49 \\
\hline Lebanon & 48 \\
\hline Australia & 42 \\
\hline India & 41 \\
\hline Jamaica & 40 \\
\hline New Zealand & 37 \\
\hline Nigeria & 36 \\
\hline
\end{tabular}

The Philippines is the country that leads the top for invention according to Google searches. Only one African country is in the top 10 when it comes to frequency of searches regarding invention, namely Nigeria.

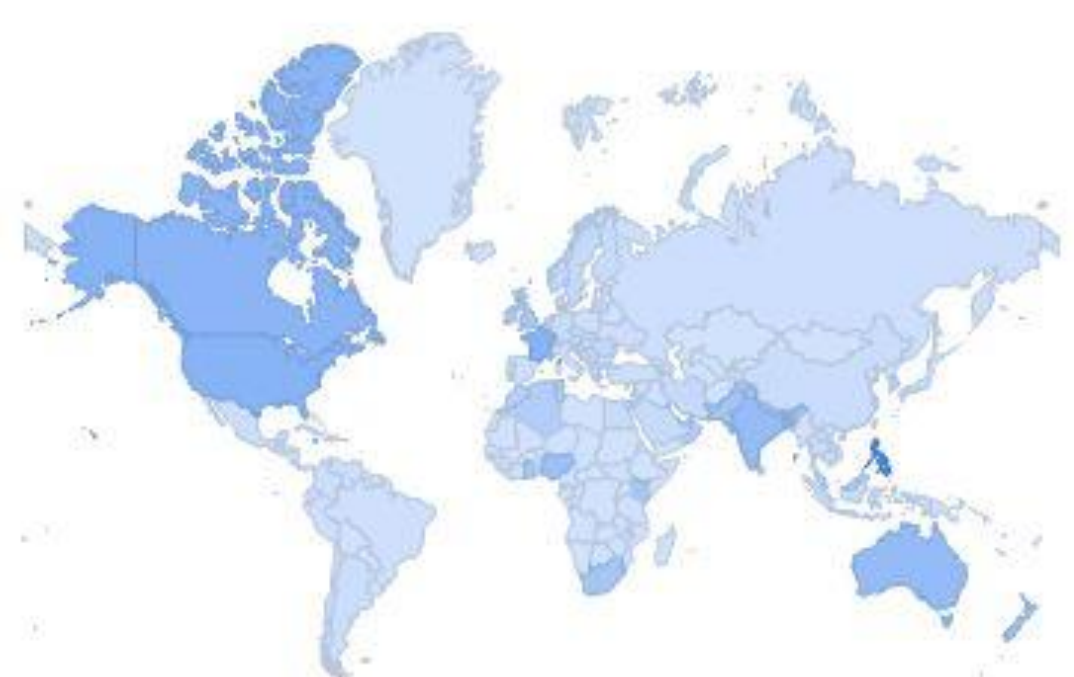

Fig. 9. Regions with high search frequency for the term invention [7]

Figure 9 depicts a map representation of the regions with high search frequency for the term invention. The search frequency is proportional to the intensity of the color blue represented on the map. Countries highlighted in dark blue are characterized by a high frequency of searches for the term invention.
The top two cities in terms of search popularity of the term invention are Makati City and Manila from the Philippines. So as opposed to the term innovation for the term invention the highest ranking country also provides the two highest ranking cities in the Google search top. 
Table 9. Search frequency top by city for the term invention [7]

\begin{tabular}{|l|c|}
\hline \multicolumn{1}{|c|}{ CITY } & SCORE \\
\hline Makati City & 100 \\
\hline Manila & 93 \\
\hline Montréal & 65 \\
\hline Paris & 52 \\
\hline New York & 44 \\
\hline New Delhi & 43 \\
\hline Chennai & 42 \\
\hline Marseille & 42 \\
\hline Washington & 41 \\
\hline Los Angeles & 41 \\
\hline
\end{tabular}

North America leads the cities' top with 4 rankings, namely New York, Washington, Los Angeles and Montréal, in the top 10 places where invention is a popular subject according to Google searches. India is in top with New Delhi and Chennai and France has Marseille and Paris.

Fig. 10. Cities with high search frequency for the term invention [7]

Figure 10 depicts a map representation of the cities with high search frequency for the term invention. Cities are represented by circles, the larger the circle the higher the search frequency. Also the search frequency is proportional to the intensity of the color blue represented on the map. Cities highlighted in dark blue are characterized by a high frequency of searches for the term invention.

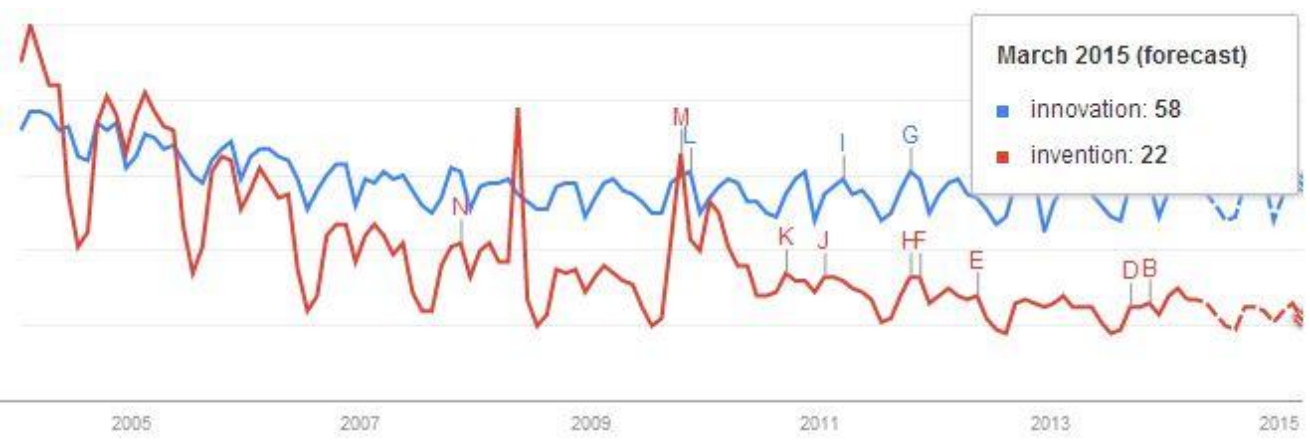

Fig. 11. Search frequency prediction for both invention and innovation [7] 
Figure 11 presents a prediction for the near future regarding the evolution of the popularity of the terms innovation and invention in Google searches. The forecast is made using Google prediction tools and it has a timespan of one year.

The dotted lines form Figure 11 represents the forecasted evolution for the two terms' popularity in Google searches.

The prediction highlighted in Figure 11 displays slight decrease in the popularity of the term innovation from 59 to 58 and also a decrees in popularity for the term invention from 27 to 22 .

\section{Public Data}

Public data is a valuable research tool and Google provides an instrument that allows taking full advantage of this resource. Google Public Data Explorer allows users to mine large datasets and access statistics and studies made available by institutions like
Eurostat, World Bank, International Monetary Fund, Organization for Economic Cooperation and Development and Harvard University. The above mention organizations are just a sample of dataset providers. Using Google Public Data Explorer a top of countries with the highest capacity for innovation was assembled. Data was made available by The World Economic Forum, a not-for-profit organization headquartered in Geneva, Switzerland [8]. Data was collected by means of survey and respondents were asked to rate how companies in their country obtain technology. Respondents had to rate their country capacity for innovation on a scale of 1 to $7 ; 1$ meaning that companies obtain technology exclusively from licensing or imitating foreign companies and 7 meaning companies obtain technology by conducting formal research and pioneering their own new products and processes. Data displayed in Figure 12 was collected in 2011.

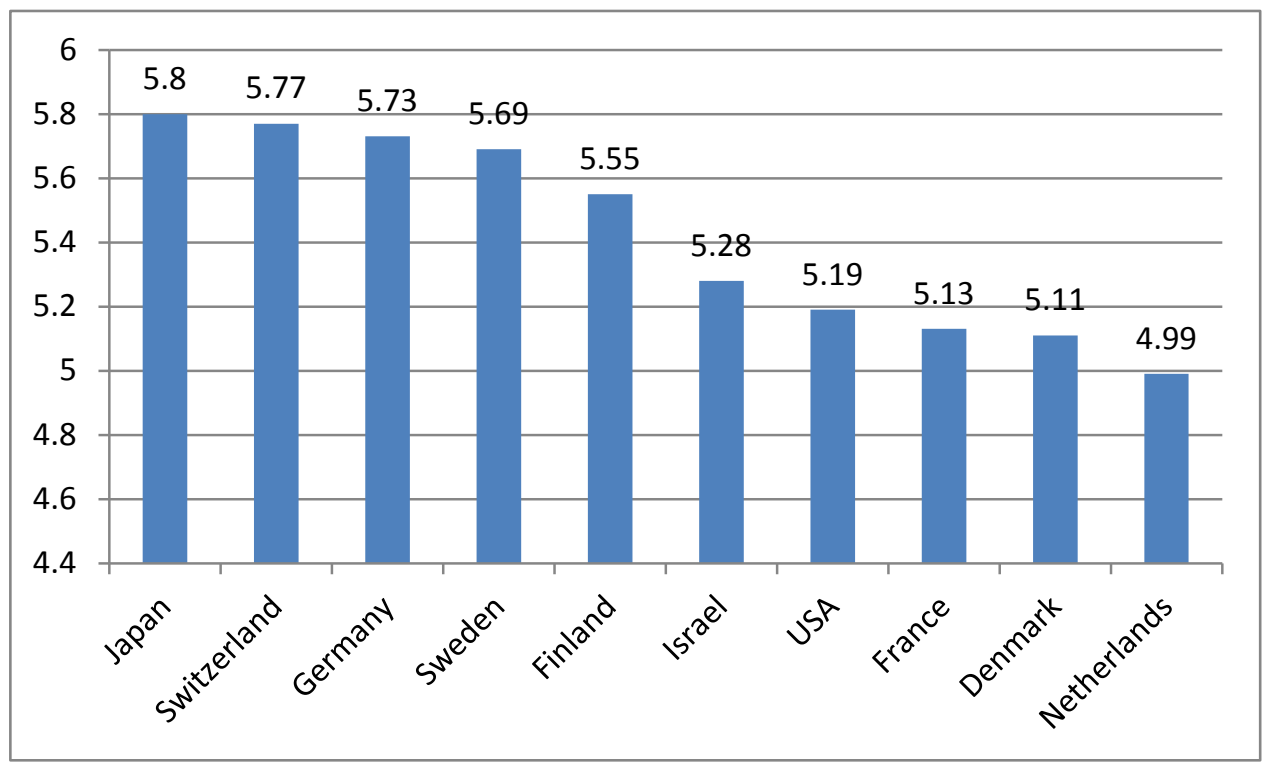

Fig. 12. Capacity for innovation [9]

According to Figure 12 the country with the most capacity for innovation is Japan. Comparing data from Figure 12 with data displayed in Table 6 reveals that only Denmark has made the top 10 in terms of capacity for innovation and interest for innovation.
In order to assess the countries capacity for invention an indicator that measures the number of utility patents per residents will be used. Data collected in Figure 13 was collected in 2010. Data was made available by The World Economic Forum. 


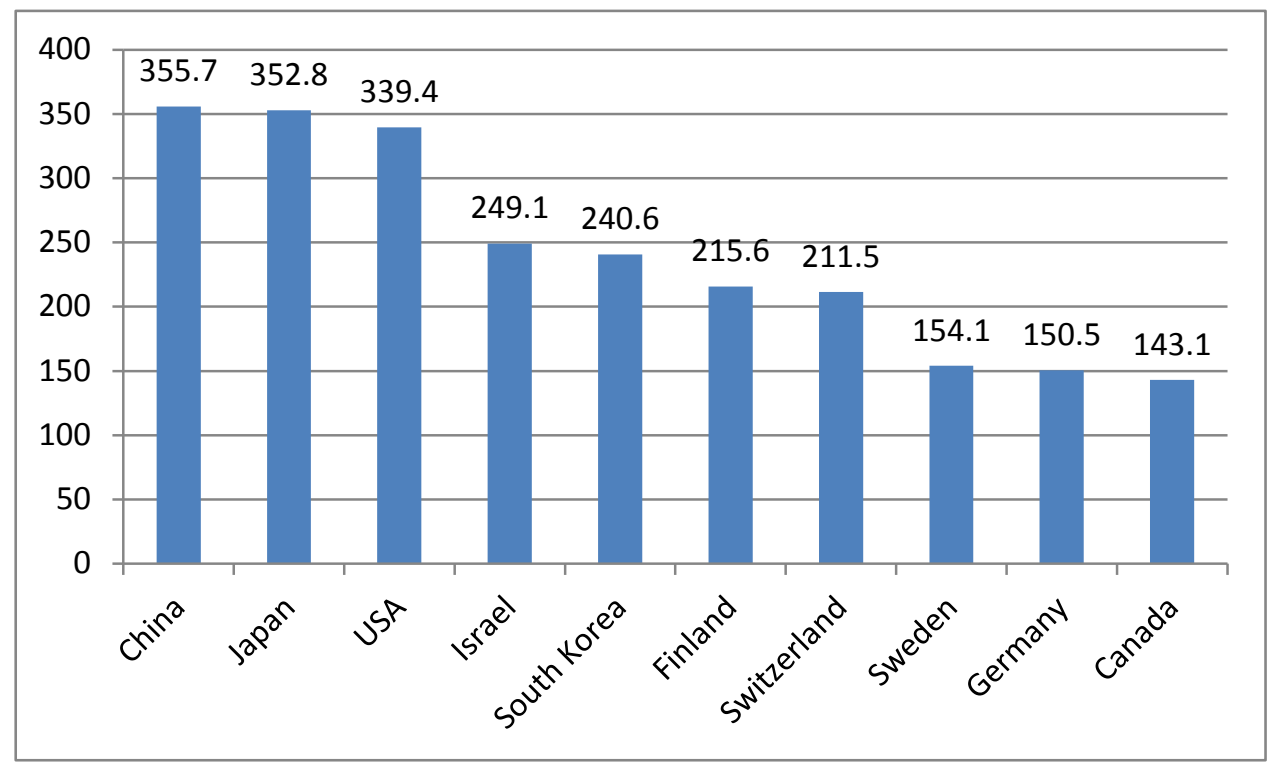

Fig. 13. Number of patents granted per million residents [9]

According to Figure 13, China is the country with the most patents granted followed closely by Japan. Comparing data from Figure 13 with data displayed in Table 8 reveals that only USA and Canada made the top 10 in terms of capacity for invention and interest for invention.

\section{Conclusions}

Innovation and invention are different concepts. Invention represents a worldwide novelty while innovation is a local novelty. Innovation is an improvement or a refinement while invention is a completely new entity. Society is interested in both innovation and invention as innovation is an economically viable invention that can be exploited in order to generate added value or to obtain profit. The evolution of society's interest in innovation and invention is determined by the number of references to both terms that can be found in a large corpus of books. Google Books shows that society's interest in invention was four times higher in the early $19^{\text {th }}$ century but the gap gradually closed and in 1972 the two terms were equally matched. After 1972 innovation began to seize society's interest. The beginning of the 21 st century saw a change in the way people acquire and share knowledge. The beginning of the $21^{\text {st }}$ century saw a change in the way people acquire and share knowledge thus using the number of occurrences of a term in books no longer accurately servers the purpose of determining society's interests and trends. The frequency of Google searches related to a certain topic becomes a more relevant indicator of society's interest. Data collected by Google depicts that African countries have a large interest in innovation. The Philippines emerges as being by far the country with the most interest channeled on invention. In order to validate the hypostasis that Google searches can determine society's interest public data is used. Data from the World Economic Forum reveals that countries that have capacity for innovation do not necessarily show an increased interest in innovation. Future development for researching trends in innovation and invention should include refining data sets as African countries have an Internet penetration rate of $16 \%$ and relevant trends are difficult to obtain using Google search results.

\section{References}

[1] J. Fagerberg, "Innovation: A guide to the Literature," Proceedings of the First Globelics Academy, Ph.D. School on National Systems of Innovation and Economic Development, 25 May - 4 Jun. 2004, Lisbon, Portugal, Publisher: Georgia Institute of Technology, URI: http://hdl.handle.net/1853/43180 
[2] M. Despa, "The adaptive nature of managing software innovation", Journal of Information Systems \& Operations Management, vol. 7, no 1, pg. 184-191, 2013

[3] http://www.osim.ro/legis/legislatie/ brevet/lgbrcont.htm

[4] B. Sanou, The world in 2013: ICT fact and figures, Feb. 2013, Available: http://www.itu.int/en/ITU-

D/Statistics/Documents/facts/ICTFactsFi gures2013.pdf

[5] https://books.google.com/ngrams

[6] http://www.google.com/trends/hottrends/ visualize?nrow $=5 \&$ ncol $=5$

[7] http://www.google.com/trends

[8] http://www.weforum.org

[9] https://www.google.com/publicdata

[10] B. Godin, Innovation: The History of a Category, Project on the Intellectual History of Innovation, working paper no. 1,2008

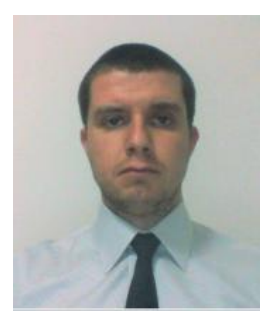

Mihai Liviu DESPA has graduated the Faculty of Cybernetics, Statistics and Economic Informatics from the Bucharest Academy of Economic Studies in 2008. He has graduated a Master's Program in Project Management at the Faculty of Management from the Bucharest Academy of Economic Studies in 2010. He is a PHD Student at the Economic Informatics PHD School and he is currently Project Manager at GDM Webmedia SRL. 